Research Paper

\title{
K-feldspar IRSL dating of a Pleistocene river terrace staircase sequence of the Lower Tejo River (Portugal, western Iberia)
}

\author{
António A. Martins ${ }^{\mathrm{a}, *}$, Pedro P. Cunha ${ }^{\mathrm{b}}$, Jan-Pieter Buylaert ${ }^{\mathrm{c}}$, Sébastien Huot ${ }^{\mathrm{d}}$, Andrew S. Murray ${ }^{\mathrm{c}}$, \\ Pedro Dinis ${ }^{\mathrm{b}}$, Martin Stokes ${ }^{\mathrm{e}}$ \\ ${ }^{a}$ Centro de Geofisica, Dep. Geociências, Univ. Évora, 7000-671 Évora, Portugal \\ ${ }^{\mathrm{b}}$ Dep. of Earth Sciences, Marine and Environmental Research Centre, Univ. Coimbra, Portugal \\ ${ }^{\mathrm{c}}$ Nordic Laboratory for Luminescence Dating, Aarhus University, Risø DTU, Denmark \\ 'Département des Sciences de la Terre et de l'Atmosphère, Université du Québec à Montréal, CP 8888, Succursale Centre-Ville, Montréal, QC, Canada H3C 3P8 \\ ${ }^{\mathrm{e}}$ School of Earth, Ocean and Environmental Sciences, University of Plymouth, UK
}

\section{A R T I C L E I N F O}

\section{Article history:}

Received 21 October 2008

Received in revised form

28 May 2009

Accepted 22 June 2009

Available online 30 June 2009

\section{Keywords:}

Optical dating

IRSL

K-feldspar

Anomalous fading

Fluvial terraces

Tejo River

Portugal

\begin{abstract}
A B S T R A C T
We present the results of K-feldspar IRSL dating of the four lower terraces (T3-T6) of the Portuguese Tejo River, in the Arripiado-Chamusca area. Terrace correlation was based upon: a) analysis of aerial photographs, geomorphological mapping and field topographic survey; b) sedimentology of the deposits; and c) luminescence dating. Sediment sampled for luminescence dating gave unusually high dose rates, of between 3.4 and $6.2 \mathrm{~Gy} / \mathrm{ka}$ and, as a result, quartz OSL was often found to be in saturation. We therefore used the IRSL signal from K-feldspar as the principal luminescence technique. The K-feldspar age results support sometimes complex geomorphic correlations, as fluvial terraces have been vertically displaced by faults (known from previous studies). Integration of these new ages with those obtained previously in the more upstream reaches of the Tejo River in Portugal indicates that the corrected K-feldspar IRSL ages are stratigraphically and geomorphologically consistent over a distance of $120 \mathrm{~km}$ along the Tejo valley. However, we are sceptical of the accuracy of the K-feldspar ages of samples from the T3 and T4 terraces (with uncorrected $D_{\mathrm{e}}$ values $>500 \mathrm{~Gy}$ ). In these cases the Dose Rate Correction (DRC) model puts the natural signals close to luminescence saturation, giving a minimum corrected $D_{\mathrm{e}}$ of about $1000 \mathrm{~Gy}$, and thus minimum terrace ages; this may even be true for those doses $>200 \mathrm{~Gy}$. Luminescence dating results suggest that: T3 is older than $300 \mathrm{ka}$, probably ca. 420-360 ka ( Marine Isotope Stage [MIS]11); T4 is ca. 340-150 ka ( MIS9-6); T5 is 136-75 ka ( $\sim$ MIS5); T6 is 60-30 ka (MIS3); an aeolian sand unit that blankets T6 and some of the older terraces is $30-\geq 12 \mathrm{ka}$. Collectively, the luminescence ages seem to indicate that regional river downcutting events may be coincident with periods of low sea level (associated, respectively, with the MIS10, MIS6, MIS4 and MIS2).
\end{abstract}

(c) 2009 Elsevier B.V. All rights reserved.

\section{Introduction}

The Tejo River is one of the major fluvial systems in southwestern Europe. It is $\sim 1000 \mathrm{~km}$ long with a catchment of $86,000 \mathrm{~km}^{2}$, and drains a significant area of the Iberian continental interior. The sedimentary and geomorphic records of this longlived (ca. 3.6 Ma) fluvial system are important for understanding late Cenozoic tectonic, climatic and eustatic controls on Iberian landscape development.

In previous research (e.g. Martins, 1999; Cunha et al., 2005, 2008; Martins et al., 2009) we have documented spatial and

\footnotetext{
* Corresponding author. Tel.: +351 266745301; fax: +351 266745397 .

E-mail address: aam@uevora.pt (A.A. Martins).
}

temporal patterns of river terrace development along some of the upstream Portuguese reaches (I, III and IV; Fig. 1). Here, the Tejo River is superimposed onto uplifted blocks of metamorphic basement, developing wide fluvial terraces in areas of soft substratum and narrow valleys in the hard substratum. In this paper we explore the application of luminescence dating to a single fluvial terrace staircase sequence and associated aeolian sediments within a relatively unstudied reach of the Tejo River that lacks absolute age control. The luminescence dating results from this study complement the existing luminescence chronologies of Cunha et al. (2008) and Martins et al. (2009) from elsewhere in the Tejo system. As in the earlier work, sediment dose rates were unusually high (3.4-6.2 Gy/ka); so, we have also chosen to use the IRSL signal from K-feldspar as the principal luminescence dating technique. Integration of new and existing luminescence age data enables us 


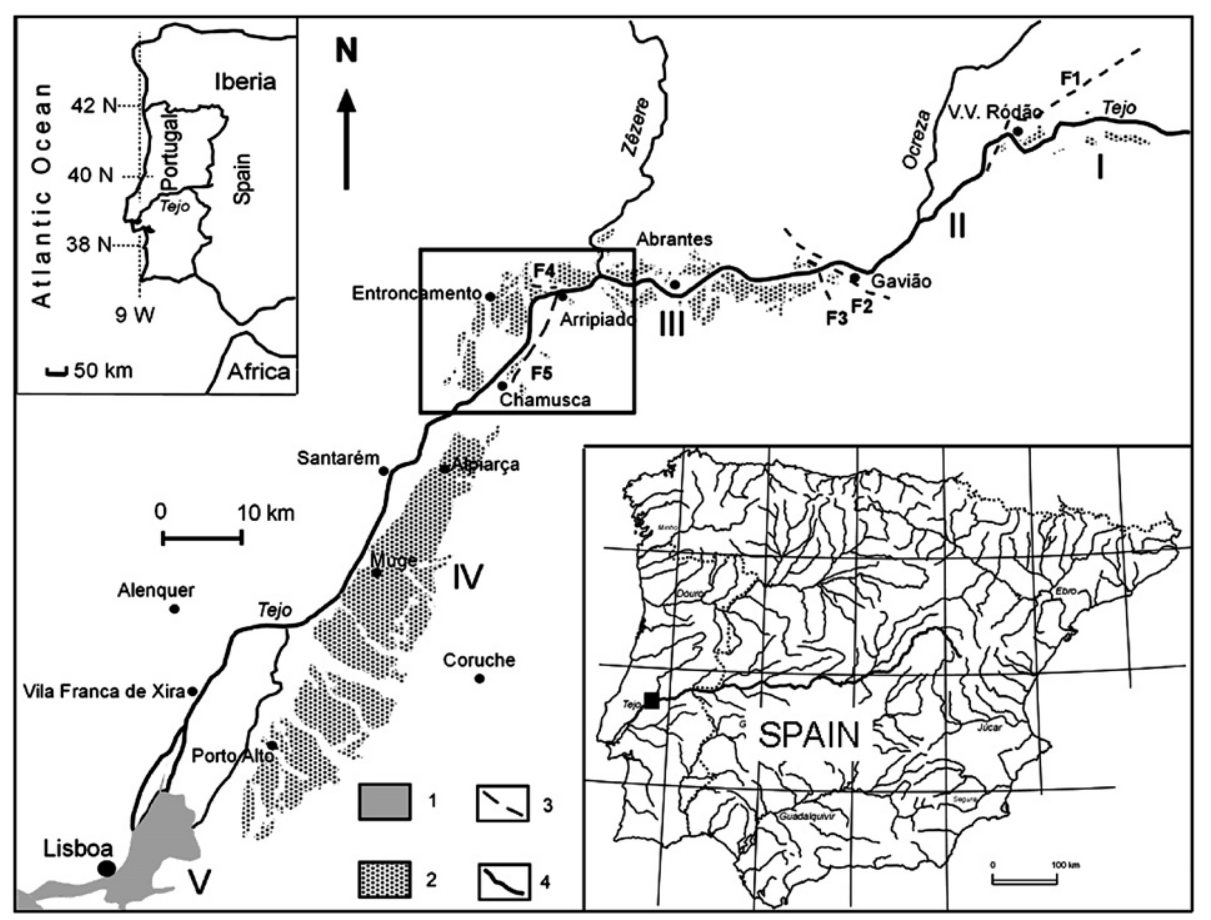

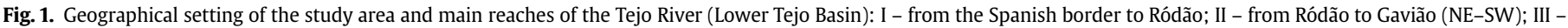

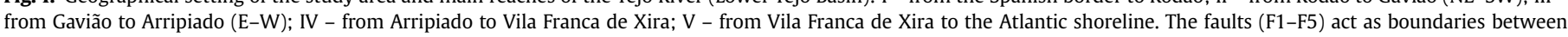
adjacent fluvial reaches. 1 - estuary; 2 - terraces; 3 - faults; 4 - Tejo main channel.

to establish a link between climate and eustatic patterns of fluvial aggradation and incision events for the four lower levels of the terrace staircase.

\section{Geologic setting}

The study area is located in the Lower Tejo Basin (LTB), a Cenozoic basin in Portugal (western Iberia) (Fig. 1). The bedrock geology comprises soft Cenozoic siliciclastic sediments and a hard Palaeozoic basement of metamorphic or magmatic origin (Fig. 2). Topographically, the study area is dominated by a plateau rising to an altitude of $190 \mathrm{~m}$ that represents the culminant surface (CS) of the LTB. This surface corresponds to the final stage of basin infilling, prior to the ongoing fluvial incision. Below this culminant surface is a staircase of six inset fluvial terrace levels (decreasing in age from $\mathrm{T} 1$ to T6). Terraces $\mathrm{T} 1$ and $\mathrm{T} 2$ are certainly outside the range of the luminescence dating technique and were not investigated here.

\section{Dating methods}

In this study thirteen new samples were dated using K-feldspar IRSL; four are aeolian sediments (Fig. 2), eight were collected from fluvial terraces and one was collected from the modern river bed (Table S1). Sand-sized $(180-250 \mu \mathrm{m}) \mathrm{K}$-feldspar grains were extracted using conventional luminescence sample preparation techniques (sieving, $\mathrm{HCl}, \mathrm{H}_{2} \mathrm{O}_{2}$, heavy liquids: $2.58 \mathrm{~g} / \mathrm{cm}^{3}$ ). The $\mathrm{K}-$ feldspar grains were etched in diluted HF (10\%) for $40 \mathrm{~min}$ to remove surface coatings and any contribution from external alpha radiation. Luminescence measurements were performed on a Risø TL/OSL DA-15 reader, with luminescence detection through a standard blue filter combination (Schott BG39 and Corning 759) (Bøtter-Jensen et al., 2003). Small (2 mm) aliquots were mounted with silicone spray on stainless steel cups. An SAR (Murray and Wintle, 2000) protocol was used to measure the $D_{\mathrm{e}}$ and $g$ values, using the same thermal treatment prior to measurement of the IRSL natural/regenerated and of the IRSL test dose signals $\left(250{ }^{\circ} \mathrm{C}\right.$ for $60 \mathrm{~s}$; Auclair et al., 2003; Huot and Lamothe, 2003). An elevated temperature IRSL cleanout $\left(290{ }^{\circ} \mathrm{C}\right.$ for $40 \mathrm{~s}$ ) was used after every SAR cycle to reduce recuperation (Buylaert et al., 2007; Wallinga et al., 2007). Optical stimulation was carried out with infrared diodes $(875 \mathrm{~nm})$ for $100 \mathrm{~s}$ at $50^{\circ} \mathrm{C}$. The initial $3.9 \mathrm{~s}$ of stimulation minus a background estimated from the last $9.2 \mathrm{~s}$ was used for all calculations. Radionuclide concentrations were measured using high-resolution gamma spectrometry of representative sub-samples (each 200-250 g; the gamma spectrometry calibration is described in Murray et al., 1987). The internal dose rates from ${ }^{40} \mathrm{~K}$ were based on an assumed $\mathrm{K}$ content of $12.0 \pm 0.5 \%$ (Huntley and Baril, 1997) and the internal contribution from $U$ and Th was taken as $0.10 \pm 0.05 \mathrm{~Gy} / \mathrm{ka}$. Total dose rates lie in the range 3.4-6.2 Gy/ka.

\section{Results}

Fig. S1 shows a sensitivity-corrected IRSL growth curve for one of the oldest samples in this study (052236, T3 terrace). Despite the very high natural dose, the natural signal can still be easily interpolated onto the growth curve, illustrating the potential of the feldspar growth curve in the high dose region (inset shows the natural IRSL stimulation curve). The $D_{\mathrm{e}}$ measurement is very reproducible and only between 6 and 10 aliquots are necessary to reduce the standard error on the mean $D_{\mathrm{e}}$ to $<3 \%$. Recycling ratios are very close to unity $(1.007 \pm 0.003, n=58)$ and recuperation is $<2 \%$ of the natural signal.

A useful SAR protocol should be able to recover a given dose prior to any heating. To test this, a dose recovery test was carried out using two different bleaching sources (IR bleaching and blue LEDs). The given dose was chosen to approximately equal the natural dose of these samples. Fig. S2 shows that there is no significant difference in dose recovery between the bleaching mechanisms. In general, the given dose is recovered within $10 \%$ 

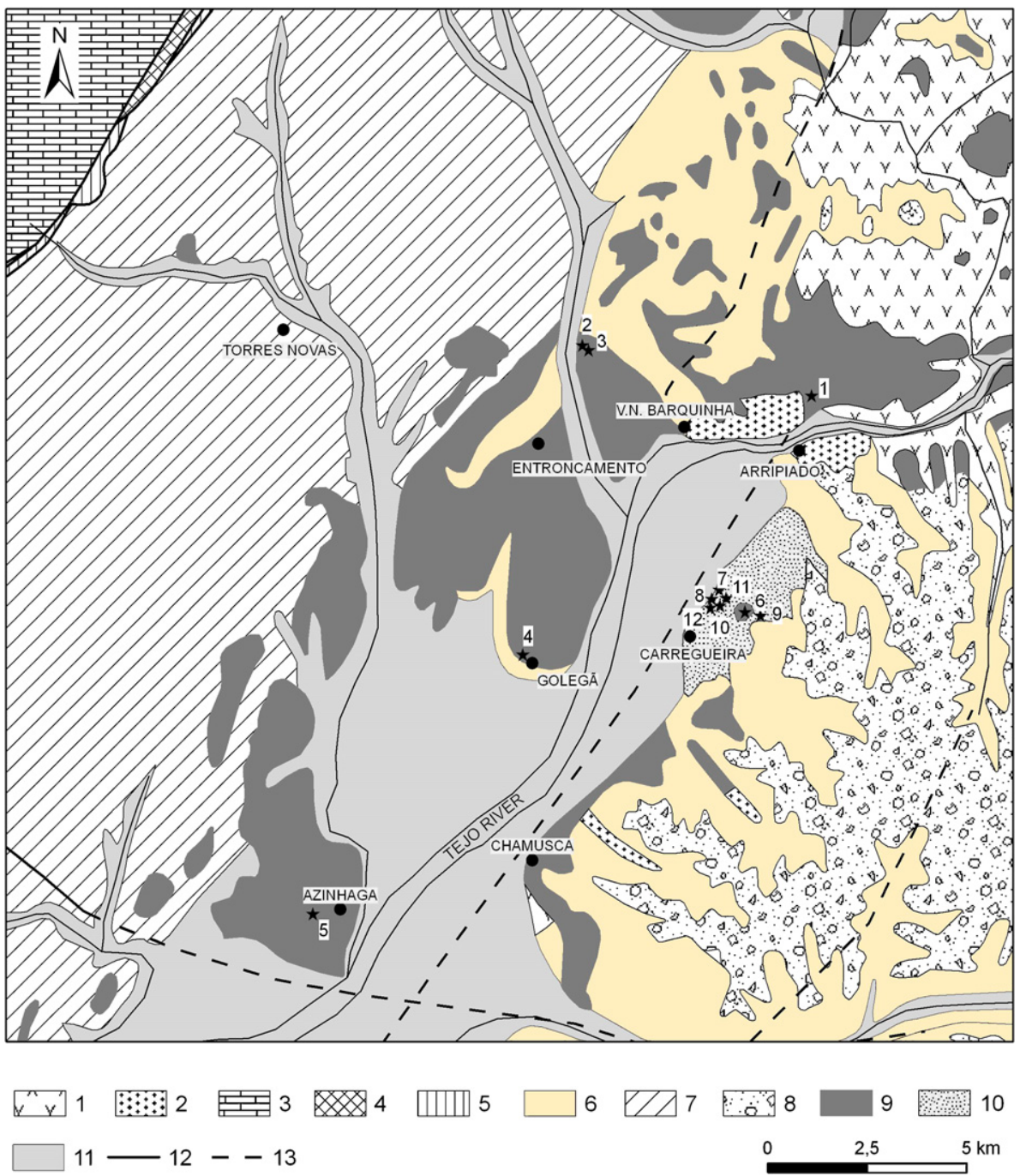

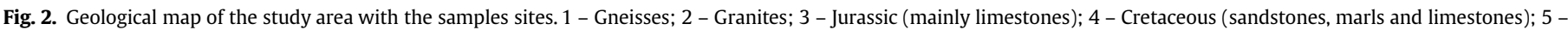

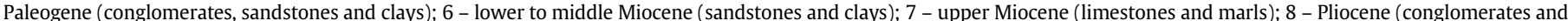
sandstones); 9 - Pleistocene (fluvial terraces); 10 - upper Pleistocene (aeolian sands); 11 - Holocene (alluvium); 12 - fault; 13 - probable fault.

although there is a tendency to systematically underestimate the given dose. We consider these results acceptable taking into account that it is at present unknown what the effect a $\sim 10 \%$ offset in dose recovery has on the $D_{\mathrm{e}}$. Furthermore, the nature of bleaching light source used to remove the natural signal may have an effect on the dose recovery test; this is known to be true for quartz (Choi et al., in press) and one can expect the same to apply to feldspars.

Given that most of our samples are fluvial in origin and feldspar IRSL bleaches slower than quartz OSL (Klasen et al., 2006) we have to check the size of the residual dose that can be expected from a modern sample. Sample 052248, collected from the modern alluvium near Abrantes (Fig. 1), has a $D_{\mathrm{e}}$ of $1.64 \pm 0.66 \mathrm{~Gy}$ which corresponds to an uncorrected age of $\sim 500$ years (Table S1). Our youngest fluvial sample is $>20 \mathrm{ka}$ so we conclude that bleaching of the Kf IRSL signal is sufficient for the samples investigated in this study.

Anomalous fading rates (normalised to a $t_{\mathrm{c}}=2$ days; Huntley and Lamothe, 2001) were measured using SAR using 3-4 prompts (immediate measurements; i.e. no delay after dosing and preheating) and delayed measurements. Our delay times were typically $20-40 \mathrm{~h}$ and a representative $g$ value measurement is shown inset in Fig. S3a. For the older samples a dose of 270 Gy was used and for the younger $\left(D_{\mathrm{e}}<100 \mathrm{~Gy}\right)$ the dose was $80 \mathrm{~Gy}$. The test dose was always $25 \%$ of the regeneration dose. The reproducibility of the prompt measurements is typically better than $0.4 \%$. Fig. S3a shows a histogram of all the $g_{2 \text { days }}$ values derived from all the aliquots measured in this study. The mean is $2.52 \pm 0.06 \% /$ decade $(n=83)$ and the distribution is relatively symmetric.

Since we have measured a fading rate on every aliquot for which we have a $D_{\mathrm{e}}$ value, we can check whether there is a correlation between these two parameters (i.e. whether low $D_{\mathrm{e}}$ values are caused by high fading rates). In Fig. S3b the $D_{\mathrm{e}}$ values (normalised to the sample average) are plotted against the $g$ value for each aliquot. No clear trend can be observed in the data set. Only for the highest fading rates (between 3.5 and $4.0 \%$ ) is there a possible weak indication of a correlation between $D_{\mathrm{e}}$ and $g$ (red symbols). For these samples, in order not to bias our results, we have fading corrected the ages based on paired $D_{\mathrm{e}}$ and $g$ values of individual aliquots. For the other samples, the sample averaged $D_{\mathrm{e}}$ and $g$ values were used. The age correction was carried out using the model proposed by Huntley and Lamothe (2001) for samples with $D_{\mathrm{e}}$ values less than $\sim 150 \mathrm{~Gy}$. It is argued by these authors that this model is only applicable to samples for which the natural signal lies 
in the "linear" part of the growth curve, although they do not define linear (of course, even close to the origin the growth curve is not expected to be truly linear). Buylaert et al. (2008, submitted for publiction) have applied the Huntley and Lamothe (2001) model and the Dose Rate Correction (DRC) model of Lamothe et al. (2003), designed for samples with natural signals in the more curving part of the growth curve, on MIS5e sites in northern Russia and Denmark, respectively. For the Russian site, with doses ranging between 120 and $170 \mathrm{~Gy}$, this model and the Dose Rate Correction (DRC) model of Lamothe et al. (2003) yield essentially the same ages, and the ages are consistent with those obtained using quartz. At the Danish site the $D_{\mathrm{e}}$ values are higher (between 160 and $220 \mathrm{~Gy}$ ) and the DRC model yields fading-corrected feldspar ages that are on average $\sim 10-15$ ka larger than those obtained with the Huntley and Lamothe (2001) correction model. The authors were unable to identify whether the Huntley and Lamothe (2001) model or that proposed by Lamothe et al. (2003) gives the most accurate estimate of age (compared to the independent age control), but they conclude that the Kf IRSL ages (corrected for fading by either model) are at least as accurate as quartz, and entirely consistent with the expected age. In this study, samples with $D_{\mathrm{e}}$ values $>150$ Gy were corrected using the DRC model. In the literature, not many papers exist that have an "old" fading-corrected feldspar IRSL ages compared with independent age control (for polymineral finegrains from loess: Buylaert et al., 2007; Auclair et al., 2007; for sand-sized K-feldspar: Buylaert et al., 2008, submitted for publication; Wallinga et al., 2007). It seems fair to state that a fading correction approach works well at least up to $\sim 200 \mathrm{~Gy}$; beyond this the results are more uncertain.

Cunha et al. (2008) and Martins et al. (2009) have shown that their fading-corrected feldspar ages from this region are in good agreement with a number of quartz OSL and U-series ages. As stated in Cunha et al. (2008), samples from the T4 and T3 terraces with uncorrected $D_{\mathrm{e}}$ values of $>500 \mathrm{~Gy}$ should be considered as minimum ages. From the previous technical discussion we deduce that the accuracy of samples $072230(377 \pm 40 \mathrm{~Gy})$ and 072229 $(282 \pm 5 \mathrm{~Gy})$ is also uncertain. The $D_{\mathrm{e}}$ values, dose rates, uncorrected ages and corrected ages are presented in Table S1.

\section{Discussion}

Integration of the new K-feldspar luminescence ages presented here with existing terrace age data (Cunha et al., 2008; Almeida et al., 2008; Martins et al., 2009) obtained from adjacent reaches (Fig. 3) indicates that: T3 is much older than $300 \mathrm{ka}$; T4 is $\leq 340$ to ca. $150 \mathrm{ka}$; T5 is $136-75 \mathrm{ka}$; T6 is $60-30 \mathrm{ka}$; and the aeolian sand unit that covers the terraces is $30-\sim 12 \mathrm{ka}$. The terrace ages can be tentatively compared with Pleistocene Marine Isotope Stages (MIS): T3 MIS11 (?); T4 MIS9-6; T5 MIS5; T6 - MIS3, suggesting that fluvial aggradation events were coincident with high sea level and warmer periods. In contrast, the periods of river downcutting should correspond to low sea level and cooler climate periods; major incision phases happened at 15?-30 ka (MIS2), 6070 ka (MIS4), and probably $\sim 140-150 \mathrm{ka}$ (MIS6). Because of the likelihood of underestimation of the Kf IRSL ages for samples with doses $>200 \mathrm{~Gy}$, the timing of downcutting events and terrace aggradation in older periods is not well defined. As a result, the attribution of MIS11 and MIS9-6 to terraces T3 and T4 respectively is simply our best estimate at present; another absolute chronometer (perhaps quartz tt-osl) should be used to test this conclusion.

The luminescence ages of the aeolian sands indicate two phases of aeolian activity (i) during the later stages of T6 aggradation and (ii) during the subsequent incision event. A single aeolian age lies in the 60-30 ka interval, a phase of significant northern hemisphere millennial timescale climatic variability (Dansgaard et al., 1993), but the majority of the aeolian ages occupy the last Pleniglacial (28$13.5 \mathrm{ka}$ ). In this time interval two Heinrich events ( $\mathrm{H} 1$ and $\mathrm{H} 2$ ) occurred, characterized by the onset of a severe cold and dry climate in the North Atlantic (Roucoux et al., 2005).

Based upon the geomorphology, river terrace stratigraphy and luminescence dating from this and previous studies, we conclude that the most likely driving mechanism for valley widening and river terrace aggradations versus periods of major fluvial incision has been base-level changes which were driven by rising and falling global sea level during Pleistocene climatic fluctuations. This climate-related base-level control is superimposed onto the

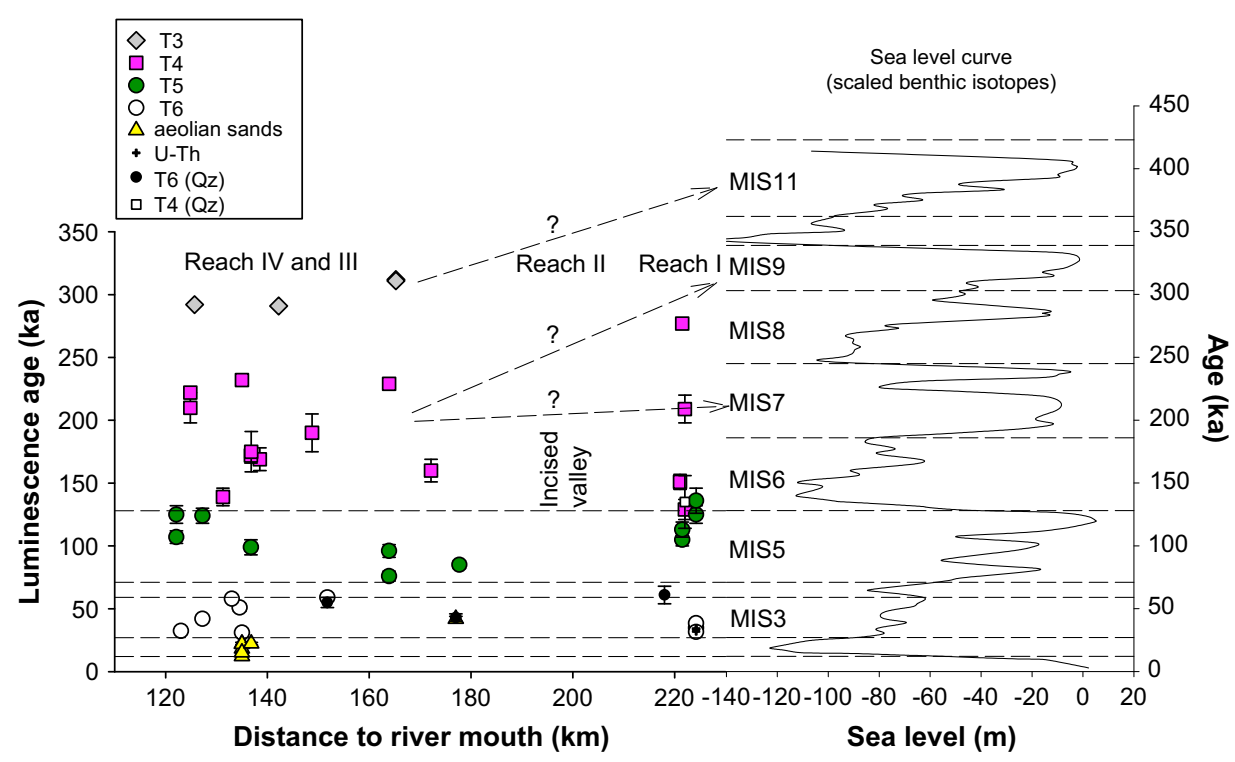

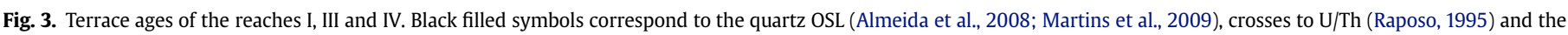

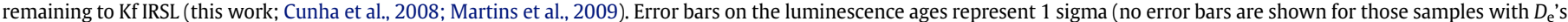

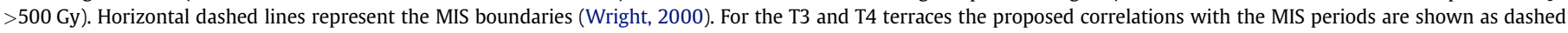
arrows and question marks. Sea level curve data comes from Cutler et al. (2003). 
longer-term (Pliocene to Holocene) trend of regional uplift-driven fluvial incision. This tectonic uplift accounts for the terrace staircase in the study area, in which terrace landforms are generally clearly separated from one another with no or little overlap between terrace bases and tops.

\section{Conclusions}

This study provides a luminescence chronology for a river terrace staircase in a previously poorly documented reach of the Lower Tejo River (Portugal). Samples for luminescence dating were obtained from the four lower terrace levels (T3-T6) and from aeolian sediments that blanket the $\mathrm{T} 6$ terrace and the eastern valley flank. As in the earlier studies, the sediments in this area have unusually high (3-6 Gy/ka) dose rates and a K-feldspar IRSL dating approach using a fading correction method was applied. The luminescence ages of this work and those previously published are consistent with geomorphological data and terrace stratigraphy over a long $(\sim 120 \mathrm{~km})$ distance. A model of river system development for the Lower Tejo, based upon an interplay between climate and tectonic activity, is proposed. Terrace genesis is attributed to Quaternary climate-related base-level fluctuations (glacio-eustasy). Integrating the fading-corrected luminescence ages of river terrace landforms from this study with previously published results suggests a general coincidence of fluvial aggradation with MIS11, MIS9-6, MIS5 and MIS3 and sea level highstands; thus major fluvial incisions have occurred during the intervening sea level lowstands. The attribution of MIS stages to major phases of river aggradation and incision is only achieved by taking into account that the older luminescence dates (say those with $D_{\mathrm{e}}$ 's $>200-250 \mathrm{~Gy}$ ) are likely to be minimum ages. These patterns are superimposed onto a longer-term regional uplift that is driving progressive fluvial incision into the western Iberian continental margin. Luminescence ages from the upper aeolian sands provide a clear cold climate signature and these sands are associated mainly with the Pleniglacial, a period of severe cold aridity and wind intensification highly favourable for aeolian activity and sand sheet deposition.

\section{Acknowledgments}

Support from the Nordic Centre of Excellence programme of the Joint Committee of the Nordic Natural Science Research Councils is gratefully acknowledged. This work is within the scope of the project PPCDT/CTE-GEX/58120/2004, approved by the Fundação para a Ciência e a Tecnologia and co-founded by the FEDER. Research was also supported by the Marine and Environmental Research Centre - Univ. Coimbra, Centro de Geofísica - Univ. Évora and Risø DTU.

Editorial handling by: R. Grün.

\section{Appendix. Supplementary data}

Supplementary data associated with this article can be found, in the online version at, doi:10.1016/j.quageo.2009.06.004.

\section{References}

Almeida, N., Deprez, S., De Dapper, M., 2008. The Palaeolithic occupation of the north-eastern Alentejo (Portugal): a geoarchaeological approach. In: BuenoRamirez, P., Barroso-Bermejo, R., Balbín-Berhmann, R. (Eds.), Graphical Markers and Megalith Builders in the International Tagus, Iberian Peninsula. BAR International Series 1765, pp. 19-25.

Auclair, M., Lamothe, M., Huot, S., 2003. Measurement of anomalous fading for feldspar IRSL using SAR. Radiation Measurements 37, 487-492.

Auclair, M., Lamothe, M., Lagroix, F., Banerjee, S., 2007. Luminescence investigation of loess and tephra from Halfway House section, Central Alaska. Quaternary Geochronology 2, 34-38.

Buylaert, J.P., Vandenberghe, D., Murray, A.S., Huot, S., De Corte, F., Van den Haute, P., 2007. Luminescence dating of old ( $>70 \mathrm{ka}$ ) Chinese loess: a comparison of singlealiquot OSL and IRSL techniques. Quaternary Geochronology 2, 9-14.

Buylaert, J.P., Murray, A.S., Huot, S., 2008. Optical dating of an Eemian site in Northern Russia using K-feldspar. Radiation Measurements 43, 715-720.

Buylaert, J.P., Huot, S., Van den haute, P., Murray, A.S. Infrared stimulated luminescence dating of an Eemian (MIS 5e) site in Denmark using K-feldspar. Quaternary Geochronology, submitted for publication.

Bøtter-Jensen, L., Andersen, C.E., Duller, G.A.T., Murray, A.S., 2003. Developments in radiation, stimulation and observation facilities in luminescence measurements. Radiation Measurements 37, 535-541.

Choi, J.H., Murray, A.S., Cheong, C.-S., Hong, S.C. The dependence of dose recovery experiments on the bleaching of natural quartz OSL using different light sources. Radiation Measurements, in press.

Cunha, P.P., Martins, A.A., Daveau, S., Friend, P.F., 2005. Tectonic control of the Tejo river fluvial incision during the late Cenozoic, in Ródão - central Portugal (Atlantic Iberian border). Geomorphology 64, 271-298.

Cunha, P.P., Martins, A.A., Huot, S., Murray, A., Raposo, L., 2008. Dating the Tejo River lower terraces in the Ródão area (Portugal) to assess the role of tectonics and uplift. Geomorphology 102, 43-54.

Cutler, K.B., Edwards, R.L., Taylor, F.M., Cheng, H., Adkins, J., Gallup, C.D., Cutler, P.M., Burr, G.S., Bloom, A.L., 2003. Rapid sea level fall and deep ocean temperature change since the last interglacial period. Earth and Planetary Science Letters 206, 253-271.

Dansgaard, W., Johnsen, S.J., Clauser, H.B., Dahl, J., Gundestrup, N.S., Hommer, C.U., Huidberg, C.S., Steffensen, J.P., Svernbjornsdottir, A.E., Jouzel, J., Bond, G., 1993. Evidence for general instability of past climate from a $250 \mathrm{kyr}$ ice-core record. Nature 364, 218-220.

Huntley, D.J., Baril, M.R., 1997. The K content of the K-feldspars being measured in optical dating or in thermoluminescence dating. Ancient TL 15, 11-13.

Huntley, D.J., Lamothe, M., 2001. Ubiquity of anomalous fading in K-feldspars and the measurement and correction for it in optical dating. Canadian Journal of Earth Sciences 38, 1093-1106.

Huot, S., Lamothe, M., 2003. Variability of infrared stimulated luminescence properties from fractured feldspar grains. Radiation Measurements 37, 499-503.

Klasen, N., Fiebig, M., Preusser, F., Radtke, U., 2006. Luminescence properties of glaciofluvial sediments from the Bavarian Alpine Foreland. Radiation Measurements 41, 866-870.

Lamothe, M., Auclair, M., Hamzaoui, C., Huot, S., 2003. Towards a prediction of longterm anomalous fading of feldspar IRSL. Radiation Measurements 37, 493-498.

Martins, A., 1999. Caracterização morfotectónica e morfossedimentar da Bacia do Baixo Tejo, Pliocénico e Quaternário. Ph.D. thesis. Universidade de Évora, Portugal

Martins, A.A., Cunha, P.P., Huot, S., Murray, A., Buylaert, J.P., 2009. Geomorphological correlation of the tectonically displaced Tejo river terraces (Gavião-Chamusca area, Portugal) supported by luminescence dating. Quaternary International 199, 75-91.

Murray, A.S., Marten, R., Johnston, A., Martin, P., 1987. Analysis for naturally occurring radionuclides at environmental concentrations by gammaspectrometry. Journal of Radioanalytical and Nuclear Chemistry 115, 263-288.

Murray, A.S., Wintle, A.G., 2000. Luminescence dating of quartz using an improved single-aliquot regenerative-dose protocol. Radiation Measurements 32, 57-73.

Raposo, L., 1995. O Paleolítico. In: Medina, J. (Ed.), História de Portugal, vol. 1. Clube Internacional do Livro, Lisboa, pp. 23-85.

Roucoux, H.K., de Abreu, L., Shackleton, N.J., Tzedakis, P.C., 2005. The response of NW Iberian vegetation to North Atlantic climate oscillations during the last 65 kyr. Quaternary Science Reviews 24, 1637-1653.

Wallinga, J., Bos, A.J.J., Dorenbos, P., Murray, A.S., Schokker, J., 2007. A test case for anomalous fading correction in IRSL dating. Quaternary Geochronology 2, 216-221.

Wright, J.D., 2000. Global climate change in marine stable isotope records. In: Stratton Noler, J., Sowers, J.M., Lettis, W.R. (Eds.), Quaternary Geochronology. Methods and Applications, pp. 427-433. 